\title{
AN INVESTIGATION INTO THE LEARNING STYLES OF FIRST YEAR STUDENTS AT INTERNATIONAL SCHOOL - THAI NGUYEN UNIVERSITY
}

\section{Nguyen Thi Phuong Thao}

TNU - International School

\begin{tabular}{|c|c|c|}
\hline \multicolumn{2}{|c|}{ ARTICLE INFO } & \multirow{4}{*}{$\begin{array}{l}\text { ABSTRACT } \\
\text { This research focused on investigating the typical learning styles of the } \\
\text { first year students at the International School - Thai Nguyen } \\
\text { University. Also, the research investigated the impact of learning styles }\end{array}$} \\
\hline Received: & $14 / 4 / 2021$ & \\
\hline & & \\
\hline Revised: & $06 / 5 / 2021$ & \\
\hline Published: & $19 / 5 / 2021$ & on their learning of English. The sample of the study consisted of 100 \\
\hline & & first year students of four different majors. The employed instruments \\
\hline \multicolumn{2}{|l|}{ KEYWORDS } & comprised the Assessing Your Learning Styles Questionnaire and \\
\hline \multicolumn{2}{|l|}{ Learning styles } & deductive, and reflective learning styles were the ones that the students, \\
\hline \multicolumn{2}{|c|}{ Teaching styles } & regardless of their majors, preferred most. Introverted and inductive \\
\hline \multicolumn{2}{|c|}{ Learning styles preference } & learning styles, on the other hand, appeared as the least preferred \\
\hline \multicolumn{2}{|l|}{ English learning } & $\begin{array}{l}\text { arning styles of the group of students. In addition, there existed } \\
\text { table similarities and differences in the learning styles preference of }\end{array}$ \\
\hline \multicolumn{2}{|l|}{ English teaching } & $\begin{array}{l}\text { the students. This study is not only useful for English teachers who are } \\
\text { interested in studying learners' learning styles, but also significant for } \\
\text { assisting teachers to apply adequate teaching methods to match the } \\
\text { students' preferred learning styles. }\end{array}$ \\
\hline
\end{tabular}

\section{NGHIÊN CỨU VỀ PHONG CÁCH HỌC TẬP CỦA SINH VIÊN NĂM NHẤT TẠI KHOA QUỐC TẾ - ĐẠI HỌC THÁI NGUYÊN}

Nguyễn Thị Phương Thảo

Khoa Quốc tế - ĐH Thái Nguyên

DOI: https://doi.org/10.34238/tnu-jst.4344

Email: thaontp@tnu.edu.vn 


\section{Introduction}

Students normally learn something in different ways. Some could learn best by seeing and hearing, reflecting and acting, reasoning logically or intuitively, analyzing and visualizing. These students' ways of learning are termed learning styles that have been a particular focus of a number of researchers over the past decades. Various studies researching into students' learning styles highlight considerable relationships between learners' styles of learning and their language learning performances and accomplishment

According to Alkhasawe Mrayyan, Docherty, Alashram, and Yosef [1], learning styles are personal qualities that influence the way students interact with their learning environment, peers, and instructors. In language learning, students should be aware of their own learning styles since it will affect their ability to develop additional learning styles and to modify their existing learning patterns [2]. In addition, Carbo and Dunn [3] stated that students who understand and then are provided opportunities to make use of their learning styles tend to feel valued, respected and empowered. It appears that addressing learners' learning styles helps them respond to the presented material in the most effective way. Even when the material is not presented in the way they prefer or the instructor has different teaching styles or the topic is not familiar, they can use their knowledge of learning styles to adjust the difference and be flexible in their learning.

It is inevitable that teaching styles and teaching techniques implemented by instructors are diverse. Some instructors prefer to lecture and others demonstrate or discuss; some focus on principles and others on applications; some emphasize memory and others understanding. In fact, the instructors usually implement their own teaching styles in class. However, no model of instruction would be the best for all situations. Katz [4] explains that teaching styles are a complex construct referring both to teachers' beliefs and actions. When a number of teachers' actions are arranged into varying patterns in order to create specific learning environments for students, it is possible to specify a particular teaching style. Moreover, it's obvious that most of the learning and teaching styles parallel each other. In accordance with Felder and Silverman [5], a student preferring intuitive over sensory perception learning style would respond well to an instructor who emphasizes abstract content rather than concrete content. In addition, a student who shows stronger preference for visual perception would be most comfortable in the class in which the instructor normally uses visual aids like charts, pictures, and films to illustrate in the lesson. It appears that the compatibility of students' learning styles and the instructors' teaching styles and techniques may yield fruitful learning outcomes. Consequently, a match between instructors' teaching styles and students' learning styles should be well recognized since it could possibly allow students to gain a deep understanding of the lessons due to the appropriate teaching techniques provided.

Since individuals have their own varied and preferred ways of learning, in every course, teachers should look for opportunities to connect to and use each of these styles to help students to be successful. Generally, students tend to employ their preferred learning style, but they can also adapt to another style if necessary. However, learners are likely to look for their preferred style in each learning situation mostly because they associate that style with learning success. Felder and Silverman [5] whose study is on the compatibility of engineering students' learning styles and the instructors' teaching styles found mismatches between common and traditional learning styles of students and traditional teaching styles of engineering professors. Consequently, the mismatches lead to negative impacts on students' learning process. Beside performing poorly on regular examinations, they were also less attentive to teachers' lectures, felt discouraged about the courses, the curriculum, and even themselves. Some students even decided to change to other curricula or withdraw from their studies. On the other hand, when encountering problems related to students' disappointing performance, poor attendance and 
hostile attitude, professors realized that something was not working; they may overly criticize their students or start to wonder whether they did the right thing in pursuing this profession.

It is evident that the compatibility of the learning and teaching styles influences learning processes. Instructors who adapt their teaching style to suit students' preferred learning styles should come close to providing an optimal learning environment for most students in a class. One common discrepancy is that most people, college age and older, are visual [6], while most college teaching is verbal. A second learning/teaching style mismatch exists when the preferred input modality of most students and the preferred presentation mode of most professors are inconsistent. On the other hand, disregarding the importance of learning styles can lead to inattentive class participants, which may affect grades and attendance rates, therefore, leading to a loss in satisfaction. Learners make the most out of information when they can select information and organize it into representations that make sense to them.

Therefore, it is also very essential and helpful for teachers to address their students' learning styles in order to meet learners' needs, to narrow the mismatch between teaching and learning styles and then to achieve the aim of the desired teaching and learning outcomes. In addition, identifying students' learning styles preferences can help the teachers design adequate tasks that can facilitate students' learning. As a result, with teachers' help, students' learning will become more effective and enjoyable.

The International School is a member unit of Thai Nguyen University, which is a central and multi-field university in the Northern Midland and Mountainous region of Vietnam. In the school, first year students have one year to learn English to prepare for learning their majors in English in the next 4 years. There exists the fact that a majority of the students lack of learning motivation. In fact, this existing reality has had a negative impact on the quality of teaching and learning at the school. In English classes, students normally feel bored and appear to be frustrated with English learning since the teachers' teaching methods do not suit their own learning styles. In fact, mismatching between teacher' learning styles and student' learning styles could reduce the learning motivation in class. Therefore, in order to find out the answer to that problem and to improve the quality of English teaching and learning, the researcher conducted a survey on the learning styles of students at the International School-Thai Nguyen University (IS-TNU)

The study was conducted to investigate the typical learning styles of non-major first year students at IS-TNU. In addition, the researcher investigated the impact of learning styles on learners' learning of English. The research aimed at finding out the answers to the following questions:

1. What are the preferred learning styles of first year students at IS-TNU?

2. What are the similarities and differences of the preferred learning styles of the first year students of different majors at IS-TNU?

\section{Methodology}

\subsection{Participants}

100 first year male and female students at the age of 19 and 20 of the International School Thai Nguyen University studying four different majors, namely International Business, Accounting and Finance, Business Administration and Environmental Management participated in the study. Most of the students live in Thai Nguyen and contiguous provinces in the region. Although some students come from mountainous areas and are ethnic minorities, majority of them have from 7 to 9 years of learning English as a foreign language at secondary school and high school. When they enter university, these first year students have one year to learn English to prepare for learning their majors in English in the next 4 years. 


\subsection{Data collection instrument and analysis}

In this study, the researcher decided to adapt some parts of the questionnaire namely "Learning Style Survey, Assessing Your Own Learning Style" designed by Cohen, Oxford, and Chito [7]. The questionnaire of the current study contains four parts representing the four different aspects of students' learning styles in general and students' learning styles of English in particular. In the questionnaire, there are four activities demonstrating the four main aspects of students' learning styles as follows: Part 1: How do I use my physical senses; Part 2: How do I expose myself to learning situation; Part 3: How do I deal with language rules and Part 4: How do I deal with response time. A format of five alternative choices was applied in the questionnaire. This means that for each questionnaire statement, five alternative selections are provided and the participants were asked to choose one from the following: $0=$ Never; $1=$ Rarely; 2 = Sometimes; 3 = Often; 4 = Always. The questionnaire was translated into Vietnamese since it seems that the translation into the participants' native language would help them understand the concept of each statement more easily and simultaneously encourage them to respond to the questionnaires willingly and promptly. Thanks to the help of English teachers teaching four classes, 100 participants completed the survey. The response rate was good and statistically significant. The collected data was put into Microsoft Excel to calculate the percentage and analyzed. In this research, the researcher also adapted the semi-structured student interviews designed by Felder [5] since it is probably the most appropriate format for the current study. After collecting data from the questionnaire, the researcher identified outstanding results which need to be clarified and explained in order to prepare corresponding interview questions.

\section{Findings and discussions}

\subsection{Students' preferred learning styles in learning English}

The percentage of typical learning styles employed by the students of four different majors: International Business, Accounting and Finance, Business Administration and Environmental Management in the four activities related to using learning styles in the learning of English are shown in Table 1.

Table 1. Percentage of students' preferred learning styles in learning English

\begin{tabular}{ccc}
\hline Activities & Learning styles & Percentage (\%) \\
\hline \multirow{2}{*}{ Activity 1 } & Visual & 36 \\
& Auditory & 34 \\
& Kinesthetic & 30 \\
\hline \multirow{2}{*}{ Activity 2 } & Extroverted & 65 \\
& Introverted & 35 \\
\hline \multirow{2}{*}{ Activity 3 } & Deductive & 61 \\
& Inductive & 39 \\
\hline \multirow{2}{*}{ Activity 4 } & Impulsive & 57 \\
& Reflective & 43 \\
\hline
\end{tabular}

As can be seen from table 1, with activity 1: How do I use my physical senses, a majority of tested students had visual preference, accounting for $36 \%$ then the second and third position was taken by auditory (34\%) and kinesthetic (30\%) respectively. In other words, IS-TNU first year students of different majors preferred learning with their eyes more than learning with their ears and learning by experience or hands-on tasks when they used physical senses to learn English. However, it is interesting to note that the results were relatively equal, precisely said, there was no big difference between preferences of the three learning styles. Therefore, the results in 
modality model are in balance, this shows the flexibility of IS-TNU first year students when they are able to learn new things using all three modalities - visual, auditory and kinesthetic.

For the second activity: How do I expose myself to learning situations, the data collected from the questionnaire reveals that there was a strong extroverted tendency among IS-TNU first year students of different majors (65\%) and just 35\% of them were introverted. This significant difference in personality model indicates that the students seem to enjoy a wide range of social, interactive tasks, including debates, discussions, conversations, games, role-plays, etc. They are also highly verbal, cooperative and ready to work with their partners in group-work.

Regarding the activity related to dealing with language rules, there was a majority of deductive learners, accounting for $61 \%$ while the number of inductive learners was very limited, only $39 \%$. In other words, deductive type appears as a strong preference among the IS-TNU first year students of the four majors, they like to go from the general to the specific, to apply generalizations to experience, and to start with rules and theories rather than with specific examples. Felder's theory [8] adds much more understanding about this result. They claim that "a large percentage of classroom teaching in every subject is primarily or exclusively deductive, probably because deduction is an efficient and elegant way to organize and present material that is already understood." (p. 26).

In terms of the last activity: How do I deal with response time, it is clear that there was much higher number of impulsive learners than reflective ones. There were only $43 \%$ of students who enjoy waiting for a while and then answer or react and there were 57\% of them prefer quick answering. This means that IS-TNU first year students of different majors are very quick or inconsiderate; they do not need much time for reaction and for their thinking. In the case of these students, thought usually follows actions.

To sum up, this section provides an overall picture on the preferred learning styles of IS-TNU first year students. However, it is very evident from the table that students of different majors presented different tendencies in using learning styles to learn English. Therefore, the next part will present an insight into the preferred learning styles of the first year students of different majors at IS-TNU.

\subsection{Similarities and differences in the preferred learning styles of the first year students of different majors at the International School-Thai Nguyen University}

First year students in different areas of studies at IS-TNU had different learning styles, generally, they favor visual, extroverted, deductive and impulsive learning styles. However, there existed some similarities and differences in the learning styles of IS-TNU first year students of different majors.

The findings of present study reveal that IS-TNU first year students of the four majors prefer the similar learning style, extroverted. According to the result of the interview, this interesting similarity exists at IS-TNU partly because the IS-TNU first year students, regardless of majors, are often given tasks relating to social and practical problems and their teachers normally require them to discuss things in groups and make presentations in front of other people so they would prefer to cooperate with others, interact with the outer world rather than working alone. Below are some examples of students' perspectives on this notion:

"I love to be involved in group work activities, the teacher normally give us chances to make presentations and play games in groups. I see these lessons like that are very interesting" (Student 1).

"My major requires us to be confident and active so I think providing us with opportunities to cooperate, to speak out in front of other people is typically essential" (Student 2).

Besides a similar preference on the extroverted learning style, the students also reported a similar preference on deductive learning style. In accordance with the result of the interview, this feature can be explained by the English background of almost IS-TNU first year students of all majors. These learners are those who have a moderate English proficiency level, their 
background is not that high, many of them come from mountainous areas with limited knowledge of English. When being asked the reasons why the students prefer the deductive learning style, some students answered:

"I learn better when the teacher gives me the rules first, then I can easily follow the instructions to make some examples myself" (Student 3).

"When I was a high school student, my English teachers often wrote the formulations of the tenses on the board then introduced the examples to illustrate the rules. I feel this teaching technique helps me understand the lesson a lot" (Student 1).

While there is no considerable difference in exposing to learning situations and dealing with language rules, when it comes to using physical senses and dealing with response time, there existed some significant differences between the learning styles preferences of the students. Among the four sub-groups of students, the economic major students (International Business, Business and Administration, Accounting and Finance) showed the strongest preference for visual learning style. According to the result of the interview, this difference exists at IS-TNU partly because the economic students' majors require them to spend much time reading materials and listening to intensive lectures so they have got more familiar to taking detailed notes. On the contrary, the environmental science major students (Environmental Management) chose visual as their minor learning style and showed the strongest preference for kinesthetic learning style. When being asked why the environmental science major students love kinesthetic learning style, some students replied:

"I don't like reading assignment. It's quite boring and repeated. I'm full of energy when joining in active games in class or participate in field trips." (Student 4)

"I enjoy being involved in active activities in class and doing experiments in the labs." (Student 5)

The collected data related to dealing with response time also reveal another difference between the learning style of the economic major students and the environmental science major students. While students of the first group show a strong preference for impulsive learning style, the second group shows the complete equality in the choice of the two learning styles: reflective and impulsive. This difference in the information-processing approaches reflects that the economic major students tend to be faster and they do not fear being wrong or making mistakes. In reality, they are not concerned enough to take the time to avoid errors.

\subsection{Discussion}

With the situation of using physical senses to learn English, although visual ranked the first place, IS-TNU first year students showed a rather equal preference for the all three learning styles. This means that these students are very flexible when they are able to learn new things by using all three channels - eyes, ears and hands-on tasks, and majority of the IS-TNU first year students are fairly well balanced on these three dimensions. As mentioned above, IS-TNU students also identified them as auditory learners. This means that these students benefit much from hearing words spoken, oral explanation, listening to audio tapes, lectures and class discussion. When auditory learners learn new things, they remember much of what they hear and more of what they hear and they say. They get a lot out of discussion, prefer verbal explanation to visual demonstration, and learn effectively by explaining things to others. In addition, IS-TNU students also showed considerable interest in kinesthetic learning style. They like to be involved in physical activities, field trips, role-playing. In class, their teacher should offer them the opportunity to participate actively in activities in the classroom and outdoor activities. With regard to self-exposing to learning situations, IS-TNU first year students strongly preferred extroverted learning styles. This means that they probably enjoy a wide range of social and interactive learning tasks like games, conversations, discussions, debates, role-plays, and simulations. This is a positive indication for a language learning environment like IS-TNU since it presents students' active style of communication and how cooperative the learners are. 
As regards impulsive and reflective learning styles, results show that IS-TNU students showed major preference for the former style. This could reflect the ways students process information generally. This reflects the fact that IS-TNU first year students like to discuss or talk about the lessons they are learning. They tend to feel more comfortable with active experimentation; so, they may not learn much in situations that require them to be passive such as most lectures. In terms of dealing with language rules, it appears that IS-TNU first year students are strongly deductive. This means that in language learning process, they prefer to be taught grammar rules first and then given specific information about the language. In the next step, they apply these rules when they use the language. This learning style is quite appropriate with the learners who mostly come from mountainous provinces with basic English background like IS-TNU first year students since this technique will encourage them to compensate for the gap in their second language knowledge by using concrete and detail communication strategies.

\section{Conclusion and implication}

\subsection{Conclusion}

It is apparent that identifying learning style is a fundamental point in language learning. Being aware of learning style of learners can provide motivation for instructors to move towards learning styles of student from their own teaching method. In addition, understanding the learning style preferences will help overcome a single style in students of a specific group. Moreover, it also helps improve teaching structure considering the students preferred teaching style and then lead to development of educational approaches. No one can deny that investigating learning styles of learners at the start of students' entrance to the university is helpful due to the following reasons. Firstly, students become aware of their own learning style and thus can select better methods to enhance their learning. Secondly, instructors become informed about their student's preferences and this allows them to use teaching methods matched with the learning styles of their students. Last but not least, graduates will have sufficient knowledge and proficiency resulting from real and effective learning.

\subsection{Implication}

In reality, when students feel unsatisfied with the way their teachers deliver the lessons, they should inform their teachers so that their teacher can find possible solutions to handle the problem and minimize the negative impacts. In addition, in order to become active and autonomous learners, students need to get more chances to balance their learning styles flexibly. In other words, they should strengthen their weaker learning styles or try to learn to move from one preferred learning style to another. Obviously, learning style is a complicated issue and in order to achieve maximize performance, identifying students learning styles then applying corresponding and adequate learning strategies should be paid great attention. It is also clear that in any classrooms, each student learns in different ways and this affects their performance considerably. Therefore, in order to succeed and achieve the best performance in learning environment, not only students but also teachers need to update themselves and find appropriate methods and strategies for learning and teaching. This implies that gaining knowledge about the learning styles of students and adapting teaching strategies appropriately are extremely important and considered to be an important responsibility of teachers. In order to avoid inconsistency between students' learning styles and instructor's teaching methods, as well as to increase motivation and improve students' performance, it is necessary for teachers to update and fit teaching methods and evaluate their efficacy. In fact, mismatch between students' learning styles and teachers' teaching styles could lead to serious consequences affecting the learning outcomes. For example, for those who are reflective learners, they need time to think thoroughly before making presentation in front of other people. However, if their teachers do not give them the 
opportunities to prepare and brainstorm, they could not perform well and then will feel hesitated, frustrated and bored with the lessons. Therefore, awareness of preferred learning styles of learners is obviously very helpful since it helps teachers identify and solve learning problems of learners significantly and simultaneously helps learners learn more efficiently.

\section{REFERENCES}

[1] I. M. Alkhasaweh, M. T. Mrayyan, C. Docherty, S. Alashram, and H. Yosef, "Problem-based learning (PBL): Assessing students' learning preferences using VARK," Nurse Education Today, vol. 28, pp.572 -579, 2008.

[2] J. Henson and C. W. Stansfield, "The relation of field-dependent-independent cognitive styles to foreign language achievement," Language Learning, vol. 31, pp. 349-367, 1981.

[3] M. Carbo, R. Dunn, and K. Dunn, Teaching Students to Read through Their Individual Learning Styles. Prentice-Hall, 1986.

[4] A. Katz, "Teaching style: A way to understand instruction in language classrooms," in Voices from the Language Classroom, K. M. Bailey and D. Nunan, Eds. Cambridge: Cambridge University Press, 1996, pp.57-87.

[5] R. M. Felder, and L. K. Silverman, "Learning and teaching styles in engineering education," 1988 Engineering Education, vol. 78, no. 7, pp. 674-681, 1988. [Online]. Available: https://www.researchgate.net/publication/257431200_Learning_and_Teaching_Styles_in_Engineering_Edu cation. Accessed March 28, 2021].

[6] W. B. Barbe, and M. N. Milone, "What We Know About Modality Strengths," Educational Leadership, vol. 70, no. 1, pp. 378-380, 1981

[7] A.D Cohen, R. L Oxford, and S. J. Chito, "Styles and strategies-based instruction: A teachers' guide," CARLA Working Paper Series, A rewritten version of paper \#7, University of Minnesota, 1990. 